\title{
EVALUATION OF THE REPRODUCIBILITY OF TWO TECHNIQUES USED TO DETERMINE AND RECORD CENTRIC RELATION IN ANGLE'S CLASS I PATIENTS
}

\author{
Fernanda PAIXÃO', Wilkens Aurélio Buarque e SILVA², Frederico Andrade e SILVA², \\ Guilherme da Gama RAMOS ${ }^{1}$, Mônica Vieira de Jesus CRUZ ${ }^{1}$
}

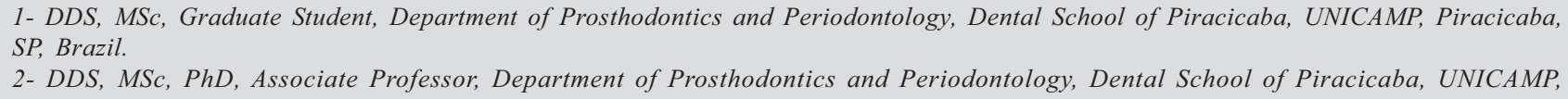

Corresponding address: Fernanda Paixão - Avenida Cillos, 562 - Vila Medon - 13465-100 - Americana, SP, Brazil - Phone: $193406-6361$ e-mail: ferpaixao@bol.com.br

Received: August 11, 2006 - Modification: September 25, 2006 - Accepted: June 13, 2007

\begin{abstract}
T

he centric relation is a mandibular position that determines a balance relation among the temporomandibular joints, the chew muscles and the occlusion. This position makes possible to the dentist to plan and to execute oral rehabilitation respecting the physiological principles of the stomatognathic system. The aim of this study was to investigate the reproducibility of centric relation records obtained using two techniques: Dawson's Bilateral Manipulation and Gysi's Gothic Arch Tracing. Twenty volunteers (14 females and 6 males) with no dental loss, presenting occlusal contacts according to those described in Angle's I classification and without signs and symptoms of temporomandibular disorders were selected. All volunteers were submitted five times with a 1-week interval, always in the same schedule, to the Dawson's Bilateral Manipulation and to the Gysi's Gothic Arch Tracing with aid of an intraoral apparatus. The average standard error of each technique was calculated (Bilateral Manipulation 0.94 and Gothic Arch Tracing 0.27). Shapiro-Wilk test was applied and the results allowed application of Student's t-test (sampling error of 5\%). The techniques showed different degrees of variability. The Gysi's Gothic Arch Tracing was found to be more accurate than the Bilateral Manipulation in reproducing the centric relation records.
\end{abstract}

Uniterms: Jaw relation record; Mandible; Temporomandibular joint; Centric relation.

\section{INTRODUCTION}

A mandibular position that determines occlusal, muscular and articular balance is fundamental to plan and execute oral rehabilitations in compliance with the stomatognathic system $^{1,2,4,5,10}$.

Historically, some debate on what should characterize optimal occlusal relationships has been found in the literature: the centric occlusion $(\mathrm{CO})$ and centric relation (CR) are conceptual positions used by clinicians as such. The term CR has received important modifications over the years.

Some researchers affirmed that the CR is an unstrained position where the mandible is in maximum retrusion ${ }^{23}$. However, others do not agree, as they consider maximum retrusion a strained position ${ }^{14}$. In 1969, Schuyler ${ }^{16}$ introduced the concept of "freedom in centric" and supported the theory that CR was rather a biological area of the temporomandibular joint (TMJ) than a point. The considerations of those authors were assessed by Dawson ${ }^{3}$
(1973), Gilboe ${ }^{5}$ (1983) and Okeson, et al. ${ }^{12}$ (1993), who stated that the $\mathrm{CR}$ should be the most anterior and superior position of the condyles at the mandibular fossa, with the articular disk interposed between them. Bear ${ }^{1}$ (1956), defined CR as a position of physiological rest, and such definition was complemented by Weinberg ${ }^{21}$ (1985) as follows: ".... The clinical $\mathrm{CR}$ is functional when the articular spaces are symmetric and both condyles are concentrically positioned in the superior portion of their respective glenoid fossa...".

Clinically, a technique that provides fidelity and reproducibility of the $\mathrm{CR}$ is essential. Therefore, several methods have been suggested for this purpose, all of them associated with the specific definitions previously mentioned $^{3,6,8,9,18}$. The aim of this study was to assess the reproducibility of two techniques used to determine and record the $\mathrm{CR}$. 


\section{MATERIALAND METHODS}

Twenty patients ( 6 male, 14 female) aged 18 to 35 years were recruited for this study after signing a written informed consent form approved by the Ethics in Research Committee of the Dental School of Piracicaba ( $n^{\circ}$ 049/2004). Inclusion criteria were: presence of 28 teeth, Angle's Class I malocclusion relationship and absence of signs and symptoms of functional alterations in the stomatognathic system.

First, irreversible hydrocolloid (Jeltrate; Dentsply Ind. and Com. Ltda., Rio de Janeiro, RJ, Brazil) impressions of both arches were taken and poured immediately with type IV stone (Durone; Dentsply Ind. and Com. Ltda., Rio de Janeiro, RJ, Brazil). Next, a face bow register was made for each patient. Superior and inferior stone casts were mounted in a dental articulator (Dentatus AB, Hägersten, Sweden) using the maximal intercuspal position (MIP).

To test the Gothic Arch Tracing technique, autopolymerizing acrylic resin (Clássico Artigos Odontológicos Ltda., São Paulo, SP, Brazil) occlusal appliances were fabricated on stone casts. A stainless steel screw was attached to the midline of the superior appliance. Thereafter, reference marks were made in the inferior appliances with a bur to positioning stainless steel plates (Figure 1). Five plates numbered from 1 to 5 were manufactured for each patient.

The intraoral apparatus was transferred to the patient's mouth, which was sat in a dental chair, with the back of the chair forming a $90^{\circ}$ angle with the floor and with the patient's head resting in the head support positioned in such a way that the Frankfort plane was parallel to the floor. The patient was instructed to execute bordering protrusive, retrusive and bilateral lateral-protrusive movements. Therefore, the Gysi's Gothic Arch was recorded in the steel plate, with the vertex of this Gothic Arch being the more retrusive position achieved by the mandible during the mandibular movements. A \#1012 round diamond (KG Sorensen Ind. Com. Ltda., São Paulo, SP, Brazil) was used to perforate $1.4 \mathrm{~mm}$ from the vertex of the Gothic $\mathrm{Arch}^{13}$. This perforation was used as a reference to obtain the $\mathrm{CR}$. This procedure was repeated during the five observation periods of this study.

To obtain the CR through Bilateral Manipulation technique, the patient was positioned with his/her thorax parallel to the ground while the dentist was sat behind the

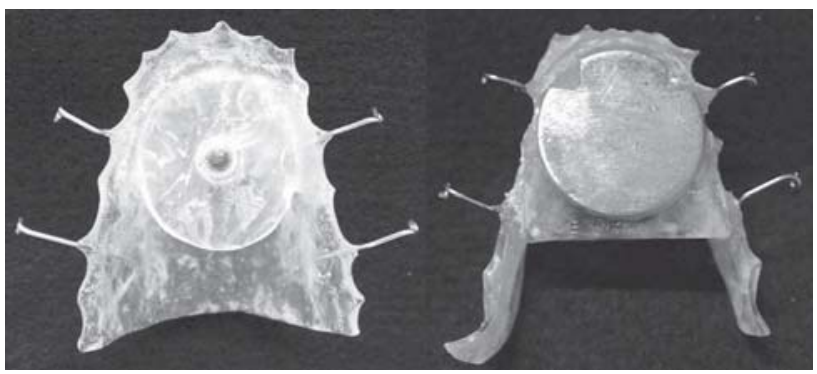

FIGURE 1- Metal screw attached to the superior acrylic resin appliance. Steel plate in the receptacle of the inferior appliance patient. In this position, the dentist was instructed to place four fingers of each hand on the lower border of the patient's mandible and then lay the thumbs over the mandibular symphysis so they would touch each other. After that, the dentist was instructed to apply firm pressure against the mandible with fingers, pressing downwards and slightly backwards with thumbs until the first interocclusal contact occurred. When this position was achieved, chemically activated acrylic resin (Duralay - Reliance Dental Mfg. Co., Worth, IL, USA) was inserted between the incisal borders of the anterior teeth, in order to construct a jig that would enable this position to be reproduced in the stone casts mounted in the articulator. All above-described procedures were also repeated for the five re-established evaluation periods. Therefore, five acrylic resin jigs were obtained per patient and numbered 1 to 5 .

Ten records of the CR position were obtained for each patient, 5 of them using the Gothic Arch Tracing technique aided by the intraoral apparatus and the other 5 by Bilateral Manipulation technique. The registers were taken five times with 1-week intervals between each register, always at the same hour of the day.

\section{Assessment of the condylar positions obtained}

To assess the obtained condylar positions, a Condylar Locator ${ }^{13}$ was adapted to the articulator. A circular piece of white cardboard was adapted to each metallic disc of the Condylar Locator to register every condylar positions obtained (Figure 2). With the stone casts mounted in MIP, a piece of red articulating paper (Arti-Fol, Articulating Film 8, Bausch Articulating Papers, Inc., Nashua, NH, U.S.A.) was inserted between each metallic pointer of the articulator and the cardboard 1 adapted to each metallic disc of the Condylar Locator. Then, the Condylar Locator was moved towards the metallic pointers in order to record with red points the bilateral position of the condyles in MIP, i.e. point " 0 ".

After, the intraoral apparatus used to obtain the $\mathrm{CR}$ by the Gothic Arch technique was adapted over the respective stone casts and the screws of the condylar elements of the articulator were released to liberate the movement of the superior ramus, which enabled the metal screw of the superior appliance to match the perforation made in the steel plate 1 of the inferior appliance. Afterwards, a piece of blue articulating paper (Arti-Fol, Articulating Film 8, Bausch Articulating Papers, Inc.) was inserted between the pointers and the same circular pieces of cardboard in order to register
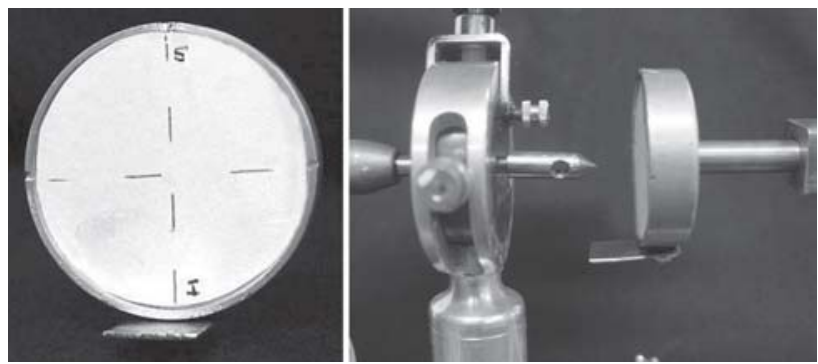

FIGURE 2- Circular piece of cardboard adapted to metallic disc. $S=$ superior, $I=$ inferior 
the condylar positions obtained by the Gothic Arch technique.

Still using the same cardboard adapted to the Condylar Locator, the superior ramus of the articulator was again liberated for adaptation of the acrylic resin jig 1 used for the $\mathrm{CR}$ register obtained through the Bilateral Manipulation. Then, a piece of black articulating paper (Arti-Fol, Articulating Film 8, Bausch Articulating Papers, Inc.) was inserted between the metallic pointers of the articulator and the first cardboards adapted to each metallic disc of the Condylar Locator to register this third position. By this method, three distinct points were obtained on the first cardboard, each one of them representing its respective condylar position on the sagital plane of both sides on the first day of this study (Figure 3).

This procedure was repeated five times for each patient in order to assess the reproducibility of the techniques used to obtain the CR. Therefore, five pairs of circular pieces of cardboard were generated with their respective records.

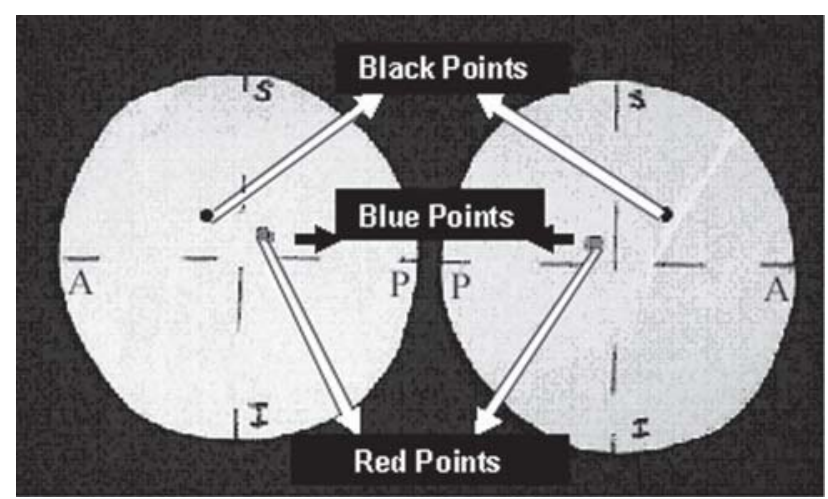

FIGURE 3- Pair of circular piece of cardboard with points delimited by the registers of the condylar positions (black, red and blue points). $S=$ superior, $I=$ inferior,$A=$ anterior, $P$ $=$ posterior

\section{Analysis of the results}

The pieces of cardboard with their respective records were analyzed on the measuring microscope (Olympus Measuring Microscope STM), and the distance between the red and the blue points and the distance between the red and the black points were measured on the horizontal plane of all cardboard. A table was drawn with these distances for statistical analysis in order to compare the differences between them and the reproducibility of the techniques under study.

\section{RESULTS}

The standard deviation of each technique for every patient was calculated considering, independently, the left and right sides. The averages between the standard deviation for the Gothic Arch Tracing technique (GA) and the standard deviation for the Bilateral Manipulation technique (BM) for both left and right sides were calculated (Bilateral Manipulation 0,94 and Gothic Arch Tracing 0,27). The averages obtained for each patient were paired and the differences between them were determined. The ShapiroWilk test was applied and the symmetry coefficient and the curtose coefficient were calculated on these differences to test normality (Table 1).

In face of these results, it was possible to verify that the data were obtained from a normal distributed population, which permitted the application of the Student's t-test for paired data (Table 2).

Student's t-test strongly demonstrated $(\mathrm{p}<0.00001)$ that the real average between the standard deviation differences is different then "0", demonstrating that the Gothic Arch Tracing and the Bilateral Manipulation techniques presented different variability degrees. Since the average of the difference was smaller than "0", it was possible to verify that the variability average of the Bilateral Manipulation technique was significantly greater than that of the Gothic Arch Tracing.

TABLE1- Study of the alternatives for selection of the most appropriate test for paired data

\begin{tabular}{lllll} 
Variable & Difference & p-value Ho: Normal & Symmetry Coefficient & Curtose Coefficient \\
\hline Difference & $\mathrm{GA}^{*}-\mathrm{BM}^{*}$ & 0.70355 & 0.31120 & -0.66365 \\
\hline
\end{tabular}

* GA - Gothic Arch Tracing technique; BM - Bilateral Manipulation technique.

TABLE 2- Average, Average Standard Error and Student's t-test for paired data of the differences of the standard deviations for the techniques GA and BM
Average $\left(G A^{*}-B M^{*}\right)$
Average Standard Error
Student's t-test
p-value Ho: $\mu=0$

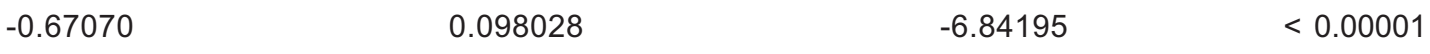

* GA - Gothic Arch Tracing technique; BM - Bilateral Manipulation technique. 


\section{DISCUSSION}

There is no standard technique to determine a mandibular position compatible with the CR. The concept of CR emerged due to the search for a reproducible mandibular position that would enable the positioning of artificial teeth during the construction of complete dentures. As the most retrusive position of the mandible in relation to the maxilla was a reproducible mandibular position, this became known as $\mathrm{CR}^{15}$.

This concept of a more retrusive mandibular position became questionable because when the mandible is in this position the space between the condyle and the posterior wall of the fossa is eliminated, which causes a compression of the retrodiscal region ${ }^{20}$. Hence, the posterior positioning of the condyle is associated with symptomatic articular conditions. Moyers ${ }^{11}$ (1956) verified that the mastication muscles showed a misbalance when the condyles were in a posterior position in the mandibular fossa. Gilboe ${ }^{5}$ (1983) and Weinberg ${ }^{19}$ (1972) affirmed that a more posterior location of the condyle is a reproducible but not a physiological position.

While considering a more posterior positioning of the condyle in the mandibular fossa as a non-physiological location, several authors $3,5,10,12,14$ began to advocate an anterior-superior condylar position as a more adequate definition of CR. Bilateral manipulation was the technique proposed to locate this position ${ }^{3}$. This technique is performed with the patient positioned in dorsal decubitus which, associated with the natural neuromuscular reaction to the mandibular manipulation method itself, makes an anterior-superior positioning of the condyles in the mandibular fossa as described, very improbable ${ }^{10}$. Our opinion goes along with authors, such as $\mathrm{McNeill}^{10}$ (2000), who affirmed that the condylar position in CR, using Bilateral Manipulation, depended not only on the manipulation method but also on the condition of the muscular activity.

Weinberg ${ }^{20}$ (1975) introduced a new concept about the subject. This author considered that the CR is a functional relation observed when there is a homogeneity and symmetry of the articular spaces in both TMJs. It was also observed that, under these conditions, the condyles should be concentrically positioned in the superior portion of their respective mandibular fossa. To position the condyles in the location described by Weinberg ${ }^{20}(1975)$ as CR, Casselli ${ }^{2}$ (2002), Ramos, et al. ${ }^{13}$ (2006) and Williamson, et al. ${ }^{22}$ (2004) proposed the use of the Gysi's Gothic Arch technique with the aid of an intraoral apparatus.

Currently, a consensual definition of CR described in the literature refers to a reproducible physiological position that is independent of occlusal contacts ${ }^{7}$. Therefore, the most posterior position and the techniques described to obtain it have been abandoned, prevailing the bilateral manipulation (anterior-superior positioning of the condyles) and the Gothic Arch tracing with the aid of an intraoral apparatus (central position of the condyles). In the present study, we evaluated the reproducibility of these two techniques as we consider such factor an important validation tool $^{7}$.

Our results revealed that, for both sides, in the articulator, the condylar positions obtained by the Bilateral Manipulation technique (black point) presented themselves in a more anterior position in relation to point " 0 " (MIP) (Figure 3). Therefore, the patients' condyles were positioned backwards, i.e., distal to MIP, as the articulator condylar position is inverse to the patients' condylar position. This patients' backwards condylar position would be predicted thanks to the force exerted upon the patients' chin. Our results agree with the observations of $\operatorname{Ramos}^{13}$ (2006), who verified the same fact in a sample of patients with the same occlusal features. The Bilateral Manipulation technique, which would place the condyles in a more anterior and superior position, is conflicting with such results.

It has been well established in this study that in the Gothic Arch Tracing technique, the vertex of this Arch and the MIP are distinct positions and therefore not coincident. These results agree with those of Gysi ${ }^{6}$ (1910), who affirmed that this vertex represents the most posterior condylar position. In accordance with this Gysi's statement, in this study, the vertex was not used as a reference to obtain the CR because the posterior condylar position is a nonphysiological position. When comparing the Bilateral Manipulation technique to the Gothic Arch Tracing, Ramos, et al. ${ }^{13}$ (2003), verified that the latert was the only that enabled the determination of the centric occlusion (CO). In that study, the author verified that between the condylar position of deglutition and the position of mastication, there is a space of approximately $1.4 \mathrm{~mm}$ on the horizontal plane anterior to the vertex, suggesting that this space is the real CR, which justifies the distance used to perforate the steel plates in our study. The perforation anterior to the Gothic Arch vertex is also supported by Casselli, et al. ${ }^{2}$ (2006), who affirmed that to obtain a maximum retrusive mandibular position, the mandible should be dislocated 1 to $2 \mathrm{~mm}$ backwards from the MIP.

Regarding the variability of the studied techniques, the Gothic Arch Tracing yielded the best results, differing significantly from the Bilateral Manipulation technique. Another important fact for reproducibility is time. According to Silva, et al. ${ }^{17}$ (1997) and Casselli, et al. ${ }^{2}$ (2006), the Gothic Arch allows verifying the muscular function, which is variable determined with the patient awaken. During sleep, for example, the muscles are more relaxed than during the day. In this study, seeking to eliminate such variable, all records, of the five periods, were made exactly at the same hour of the day.

The results obtained in this study demonstrate that perhaps the most important is not the acquisition of the CR by any technique as a rehabilitation position, but rather the determination of the $\mathrm{CO}$, as a location that allows the physiological dislocation of the condyles backwards, favoring deglutition without any intra-articular compression. Therefore, a technique with a smaller variability and greater reproducibility for the determination of $\mathrm{CR}$ and consequently CO should be used. 


\section{CONCLUSION}

Based on the results of this study, it may be concluded that the studied techniques demonstrated different variability degrees, considering that the Gothic Arch Tracing technique with the aid of an intraoral apparatus proved to have greater reproducibility than Bilateral Manipulation.

\section{REFERENCES}

1- Bear PN. An analysis of physiologic rest position, centric relation and centric occlusion. J Periodontol. 1956;27:181-4.

2- Casselli H, Silva FA, Landulpho AB, Silva WAB. Avaliações eletrognatográficas em pacientes edêntulos. Pesqui Odontol Bras. 2006;20:56

3- Dawson PE. Temporomandibular joint pain-dysfunction problems can be solved. J Prosthet Dent. 1973;29(1):100-12.

4- George JP. New definition of relating occlusion to varying conditions of temporomandibular joint [letter]. J Prosthet Dent. 1996;76(1):105-6.

5- Gilboe DB. Centric relation: functional anatomy. J Can Dent Assoc. 1983;49(5):345-8.

6- Gysi A. The problem of the articulation. Part I. Dent Cosmos. 1910;52(1):1-19.

7- Keshvad A, Winstanley RB. An appraisal of the literature on centric relation. Part III. J Oral Rehabil. 2001;28(1):55-63.

8- Long JH Jr. An instrument for locating centric relation. J Prosthet Dent. $1973 ; 30(1): 50-2$

9- Lucia VO. Centric relation, theory and practice. J Prosthet Dent. $1960 ; 10(5): 849-56$.

10- McNeill C. Occlusion: what it is and what it is not. J Calif Dent Assoc. 2000;28(10):748-58.

11- Moyers RE. Some physiologic considerations of centric and other jaw relations. J Prosthet Dent. 1956;6(2):183-94.

12- Okeson JP, Carlson CR, Falace DA, Nitz AJ, Curran SL, Anderson D. Comparison of psychologic and physiologic functioning between patients with masticatory muscle pain and matched controls. J Orofac Pain. 1993;7(1):15-22.

13- Ramos GG, Casselli H, Silva LLB, Silva FA, Silva WAB. Avaliação de duas técnicas para a obtenção da relação cêntrica em pacientes classe I de Angle. Pesqui Odontol Bras. 2006;20:249.

14- Rinchuse DJ, Kandasamy S. Centric relation: a historical and contemporary orthodontic perspective. J Am Dent Assoc. 2006;137(4):494-501.

15- Schuyler CH. Fundamental principles in the correction of occlusal disharmony: natural and artificial. J Am Dent Assoc. 1935;22(7):1193202 .

16- Schuyler CH. Freedom in centric. Dent Clin North Am. $1969 ; 13(3): 681-6$.

17- Silva FA, Figueiró C, Silva WAB, Henriques GEP. Electromyographic evaluation after treatment with occlusal splints with drills. J Dent Res. 1997;76(5):1011-7.
18- Silverman MM. Centric occlusion and jaw relations and fallacies of current concepts. J Prosthet Dent. 1957;7(6):750-69.

19- Weinberg LA. A correlation of temporomandibular dysfunction with radiographic findings. J Prosthet Dent. 1972;28(5):519-39.

20- Weinberg LA. Superior condylar displacement; its diagnosis and treatment. J Prosthet Dent. 1975;34(1):59-76.

21- Weinberg LA. Optimum temporomandibular joint condyle position in clinical practice. Int J Periodontics Restorative Dent. $1985 ; 5(1): 10-27$.

22- Williamson RA, Williamson AE, Bowley J, Toothaker R. Maximizing mandibular prosthesis stability utilizing linear occlusion, occlusal plane selection, and centric recording. J Prosthodont. 2004;13(1):55-61

23- Wilson PH, Banerjee A. Recording the retruded contact position: a review of clinical techniques. Br Dent J. 2004;196(7):395-402. 